\title{
A meta-analysis of ECG abnormalities (arrhythmias) in different types of heart failure
}

\author{
Aref Albakri* \\ St-Marien Hospital Bonn Venusberg, Department of Internal Medicine, Bonn, Germany
}

\begin{abstract}
The present paper performed a meta-analysis of 11 heart failure (HF) registries and 22 studies $(\mathrm{N}=292,927$; mean age=71.8 years; females=43\%) that evaluated arrhythmias in HF. The aim was to determine the prevalence and common types of arrhythmias in different forms of HF. Despite the prevalence of arrhythmias in all forms of heart failure (HF) and their association with a substantial risk of hospitalization, morbidity, and mortality, the search for studies finds that ECG-defined arrhythmias remain an understudied pathology in HF populations. Original studies on arrhythmias in HF populations are lacking, with a majority only reporting atrial fibrillation $(\mathrm{AF})$ and ventricular tachycardia or fibrillation (VT/VF) during index admission as the underlying disease or precipitating factor. VT/VF received disproportionate focus because they confer substantial risk of thromboembolism and sudden cardiac death, respectively. The event rate of AF was 32.7\% (95\% CI: 31.1-34.3) and VT was 32.0\% (95\% CI: 12.2-61.3) in the 11 registries and AF occurred in 32.7\% (95\% CI: 32.5-33.0) in the $22 \mathrm{HF}$ studies. Data on the prevalence of other forms of arrhythmias was either unavailable or insufficient for a pooled analysis. The prevalence of AF was observed in hypertensive HF, HF with reduced/ preserved ejection fraction, right HF, systolic HF, ischemic HF, and thyrotoxic HF. Given that arrhythmias can be both a cause and a consequence of HF, it is important to determine the prevalence of the different types of arrhythmias in different HF populations to improve diagnosis and refine management.
\end{abstract}

\section{Introduction}

Arrhythmias are abnormalities in the heart rate or rhythm caused by an aberrant electrical impulse origination and/or propagation. The most common and life-threatening forms are supraventricular arrhythmias (SVA) that arise from above the atrioventricular (AV) node and include atrial fibrillation (AF), atrial flutter, and paroxysmal supraventricular tachycardia. The other common and potentially life-threatening arrhythmias are ventricular arrhythmias that arise from the AV junction or within the AV node itself and include ventricular fibrillation (VF) and ventricular tachycardia (VT). The other less prevalent and potentially non-lethal forms of arrhythmias include bradyarrhythmias and extra beats such as premature atrial contractions, premature ventricular contractions (PVC), extrasystoles, and premature junctional contractions. In an alternative definitios, changes in heart rate above or below the normal adult range of 60 to 100 beats per minute (bpm) are termed tachycardia (a faster heart rate $>100 \mathrm{bpm}$ ) or bradycardia (a slower heart rate $<60 \mathrm{bpm}$ ) [1,2].

Arrhythmias are common in patients with heart failure (HF), especially those with concomitant ischemic heart disease and reduced left ventricular ejection fraction, in which they add a substantial risk of hospitalization, morbidity, and mortality [3-5]. The relationship between arrhythmias and HF is double-sided. On the one hand, the progression of HF predisposes the myocardial tissues to arrhythmias and increases their prevalence in the HF population. On the other hand, arrhythmias may aggravate pre-existing HF by precipitating acute decompensation or by a progressive deterioration of the cardiac function [4]. The probability that AF precedes CHF or vice versa is similar and can deteriorate each other to complicate guideline-directed therapy. Among arrhythmias, AF and VT/VF have drawn substantial attention because they are associated with an ominous prognosis and an increased risk of mortality [6]. In particular, HF and AF have emerged as new cardiovascular epidemics over the past two decades. Although the incidence has remained relatively the same over the past three decades, survival has improved substantially, leading to a significant increase in the prevalence of $\mathrm{HF}$ and $\mathrm{AF}$ among geriatric population $[7,8] . \mathrm{AF}$ is the most common sustained cardiac rhythm disorder associated with an elevated risk of stroke and thromboembolism [9], while ventricular arrhythmias increase the risk of sudden cardiac death (SCD) [10]. Bradyarrhythmias commonly manifest as sinus node dysfunction, tachy-brady syndrome (alternating bradycardia and tachycardia), and conduction disease [11].

Electrocardiogram (ECG) is a valuable first-line investigation tool for patients suspected with HF recommended by both the European Society of Cardiology (ESC) [12] and American College of Cardiology Foundation/American Heart Association (ACCF/AHA) guidelines on the diagnosis and management of HF [13]. However, ECG is specifically pathognomonic in only a few situations and lacks consensus among clinicians and electrocardiographers about pathologic interpretations of the majority of ECG abnormalities or their implications for cardiac status, prognosis, or response to therapy [14]. Nonetheless, ECG is valuable in ruling out HF because it is unlikely for HF patients to have a completely normal ECG. However, an abnormal ECG does not necessarily mean a diagnosis of HF. Instead, it is useful for pre-selecting individuals with a suspected diagnosis of $\mathrm{HF}$ for a further non-invasive echocardiographic investigation $[12,13]$. Besides HF, ECG is the main

*Correspondence to: Aref Albakri, St-Marien Hospital Bonn Venusberg, Department of Internal Medicine, Bonn, Germany, E-mail: arefalbakri@yahoo.com

Key words: arrhythmias, atrial fibrillation, ventricular tachycardia\}, electrocardiography, heart failure

Received: April 10, 2020; Accepted: April 23, 2020; Published: April 28, 2020 
test for detecting arrhythmias. Since the current ESC and ACCF/AHA guidelines recommend that all HF patients should undergo ECG tests, the present paper performs a meta-analysis of studies evaluating ECG on HF patients to determine the prevalence and type of arrhythmias in different morphological or functional and aetiological forms of HF.

\section{Eligible studies}

This meta-analysis analyzes the prevalence of arrhythmias in different types of HF based on functional and aetiological classification. The search strategy, including study selection, data extraction, and analyses followed the guidelines outlined in the preferred reporting items for systematic reviews and meta-analyses (PRISMA) [15]. The comprehensive search included electronic database search on PubMed and manual search of the American Journal of Cardiology and the Journal of the American College of Cardiology, the top two cardiology journals based on the frequency of publication of diagnostic evaluation studies, and citation searches of identified included studies and reviews. Search terms included a range of text words and MeSH terms concerning the condition of interest (heart failure) and diagnostic test of interest (ECG). The excluded studies included those that evaluated animal models of $\mathrm{HF}$ and/or arrhythmia.

\section{Patient characteristics}

\section{Heart failure registries}

The final dataset of the present meta-analysis comprised of 33 studies that reported absolute numbers or percentages of ECG-defined arrhythmias in HF patients. The included studies comprised of 11 national registry analyses: ADHERE [16], OPTIMIZE-HF [17], EHFS II [18], EFICA [19], ESC-HF Pilot [20], RO-AHFS [21], ALARM-HF [22], AHEAD [23], In-HF Outcome [24], GWTG-HF [25], and ATTEND [26] (Table 1). Patient characteristics in the 11 registry studies included a total population of $292,927 \mathrm{HF}$ patients, mean age 71.8 years (95\% CI: 40.5 to 71.0 ) with a slightly lower proportion of female patients (43\%). The national registries provided personal and clinical data about HF patients from seven different countries located across three continents - America, Europe, and Asia - the U.S. [16,17,25], Europe [18,20], France [19], Romania [21], Czech Republic [23], Italy [24], and Japan [26]. The study analyzed an international registry that included data from nine countries located in four continents - France, Germany, Italy, Spain, UK, Greece, Turkey, Australia, and Mexico [22].

Although the registries provide valuable data on HF patients, including the prevalence of arrhythmias, the primary purpose of HF registries is to evaluate the prevalence, clinical presentation, management, and outcomes of HF across different countries and patient populations. Consequently, the HF registries did not discriminate against the type of HF. Instead, they included several various forms of $\mathrm{HF}$ - reduced ejection fraction (HFrEF), preserved ejection fraction (HFpEF) and mid-range ejection fraction (HFmEF), high or low cardiac output HF, right HF, hypertensive HF, cardiogenic shock, thyrotoxic $\mathrm{HF}$, ischemic HF, systolic HF, and acute decompensated HF.

In addition, the registries did not individually evaluate different types of arrhythmias but focused on AF, which they perceived as an emerging epidemic among HF patients. The purpose of gathering patient history and characteristics on index admission was to identify the underlying diseases and the precipitating factors for the HF. The registries listed arrhythmias, either underlying diseases or precipitating factors. In particular, the registries only listed absolute cases or percentages of AF, and a few others on cases of VT. The registries mentioned other less prevalent or less-lethal types of arrhythmias in brief when discussing clinical management but did not quantify their data to enable a pooled analysis. Overall, based on the registries, besides $\mathrm{AF}$, arrhythmias are a common but overlooked manifestation of HF.

\section{Heart failure studies}

Besides HF registries, the final dataset also included $22 \mathrm{HF}$ studies that enrolled a small-size or moderate-size HF cohorts [27-48] (Table 2). Patient characteristics in the included 22 studies [27-48] were a sample population of $147,319 \mathrm{HF}$ patients, with an almost equal male to female representation ( $48.8 \%$ female patients) and relatively older (68.8 years; 95\% CI: 68.7 to 68.9 years). The 22 studies included countries in America (the U.S and Canada), Europe (the U.K., Netherlands, Denmark, and the Czech Republic), Asia (Japan, Pakistan, India), and Africa (subSaharan Africa, Nigeria, and Ghana). Together, the11 registries and 22 HF studies only evaluated a few types of HF, which included thyrotoxic HF [27-31], HFrEF [18,23,25,32-34,36-40], ischemic [34,41], HFpEF $[25,35]$, HFmEF [25], hypertensive [18,23,26,47,48], right HF [18], and systolic HF [42-46].

Despite individual studies enrolling patients diagnosed with a specific type of HF, the definitions were overlapping, suggesting that HF types are not distinct but may share many common clinical characteristics. The bulk of the studies defined HF types based on structural and/or functional abnormalities. These studies mostly categorized HF by quantifying LVEF into HFrEF, HFpEF, HFmEF, and systolic HF [18,23,25,32-34,35-46]. Other studies categorized HF type based on the causative agent rather than functional changes but, in effect, relied on LVEF values to confirm HF diagnosis. These studies categorized HF into hypertensive, ischemic and thyrotoxic [27$31,34,41,47,48]$. Thus, based on the classification adopted, the different types of HF may share common clinical characteristics.

Table 1. Prevalence of arrhythmia in HF patient registries

\begin{tabular}{|c|c|c|c|c|c|c|}
\hline Study [Ref\#] & Country & Sample & Age (Yrs.) & Female (\%) & AF \\
\hline ADHERE [16] & U.S. & 105388 & $72.4 \pm 14.0$ & 52 & 32670 \\
\hline OPTIMIZE-HF [17] & U.S. & 48612 & $73.1 \pm 14.2$ & 52 & 14970 \\
\hline EHFS II [18] & Europe & 3580 & $69.9 \pm 12.5$ & 39 & 1385 \\
\hline EFICA [19] & France & 581 & $73 \pm 13$ & 41 & 145 \\
\hline ESC-HF Pilot [20] & Europe & 5118 & $70 \pm 13$ & 37 & 1791 \\
\hline RO-AHFS [21] & Romania & 3224 & $69.2 \pm 11.8$ & 44 & 14 \\
\hline ALARM-HF [22] & International & 4953 & NR & 38 & 1209 \\
\hline AHEAD [23] & Czech Republic & 4153 & $71.5 \pm 12.4$ & 42 & 119 \\
\hline In-HF Outcome [24] & Italy & 1855 & $72 \pm 12$ & 40 & 1101 \\
\hline GWTG-HF [25] & U.S. & 110621 & $74 \pm 14$ & 47 & \\
\hline ATTEND [26] & Japan & 4842 & $73.0 \pm 13.8$ & 42 & \\
\hline
\end{tabular}

AF: Atrial Fibrillation; VF: Ventricular Fibrillation; VT: Ventricular Tachycardia 
Table 2. Characteristics of the included studies

\begin{tabular}{|c|c|c|c|c|c|c|}
\hline 1st Author, Year [Ref \#] & Country & Cohort Type & Sample Size & Age (Yrs.) & Female (\%) & AF/ Flutter (n) \\
\hline Yen, 1960 [27] & China & Thyrotoxic HF & 135 & NR & 74 & 4 \\
\hline Osman, 2007 [28] & U.K & Thyrotoxic HF & 393 & 49 & 74 & 22 \\
\hline Satpathy, 2013 [29] & India & Thyrotoxic HF & 72 & $15-65$ & 72 & 6 \\
\hline Goyal, 2016 [30] & India & Thyrotoxic HF & 50 & 33.9 & 76 & 3 \\
\hline Baladi, 2018 [31] & Pakistan & Thyrotoxic HF & 103 & $30.09 \pm 5.57$ & 82 & 12 \\
\hline Stevenson, 1996 [32] & U.S. & HFrEF & 356 & $54 \pm 12$ & 21 & 73 \\
\hline Cuffe, 2002 [33] & U.S & HFrEF & 949 & 65 & 29 & 302 \\
\hline Borleffs, 2009 [34] & Netherlands & Ischemic HF & 391 & $51 \pm 12$ & 24 & 93 \\
\hline \multirow[t]{2}{*}{ Karaye, 2008 [35] } & Nigeria & HFrEF & 71 & $44.9 \pm 17.8$ & 44 & 10 \\
\hline & & HFpEF & 42 & $39.3 \pm 18.9$ & 27 & 8 \\
\hline Familoni, 2007 [36] & Nigeria & HFrEF & 82 & $57.6 \pm 15.9$ & 33 & 17 \\
\hline Karaye, 2008 [37] & Nigeria & HFrEF & 79 & $46.9 \pm 17.89$ & 44 & 15 \\
\hline Connolly, 2011 [38] & Canada, U.S., Europe & HFrEF & 5591 & $70 \pm 9$ & 43 & 3856 \\
\hline Kelder, 2011 [39] & Netherlands & HFrEF & 207 & $75.5 \pm 9.7$ & 60 & 43 \\
\hline Dzudie, 2014 [40] & Sub-Saharan Africa & HFrEF & 523 & $52 \pm 18.4$ & 51 & 121 \\
\hline ATTEND [26] & Japan & Hypertensive & 1362 & $74.8 \pm 12.3$ & NR & 536 \\
\hline \multirow[t]{3}{*}{ EHFS II [18] } & Europe & HFrEF & 2340 & $69.7 \pm 12.8$ & 38 & 966 \\
\hline & & Hypertensive & 407 & $69.8 \pm 11.2$ & 40 & 152 \\
\hline & & Right HF & 113 & $69.6 \pm 13.4$ & 50 & 66 \\
\hline \multirow[t]{4}{*}{ AHEAD [23] } & Czech & HFrEF & 2241 & $73.8(48.5-87.6)$ & 40 & 634 \\
\hline & & Hypertensive & 179 & $74.8(49.3-88.7)$ & 65 & 34 \\
\hline & & High Output & 132 & $76.2(51.0-91.1)$ & 53 & 97 \\
\hline & & Right HF & 156 & $65.8(35.3-84.9)$ & 44 & 30 \\
\hline \multirow[t]{3}{*}{ GWTG-HF [25] } & U.S. & HFrEF & 55083 & $70(58-80)$ & 36 & 15423 \\
\hline & & HFpEF & 40354 & $78(62-83)$ & 63 & 13720 \\
\hline & & HFmEF & 15184 & $76(65-84)$ & 47 & 5162 \\
\hline Borleffs, 2009 [41] & Netherlands & Ischemic $\mathrm{HF}+\mathrm{ICD}$ & 412 & $63 \pm 11$ & 12 & 98 \\
\hline Hutcheon, 2002 [42] & U.K. & Systolic HF & 299 & $79(61-98)$ & 65 & 46 \\
\hline Khan, 2007 [43] & International & Systolic HF & 9315 & $71 \pm 13$ & 46 & 2486 \\
\hline Devkota, 2016 [44] & U.S & Systolic HF & 157 & & 39 & 21 \\
\hline Olesen, 2016 [45] & Denmark & Systolic HF & 260 & $80(75-92)$ & 52 & 75 \\
\hline Aro, 2017 [46] & U.S. & Systolic HF & 9674 & $68.7 \pm 17.3$ & 46 & 3599 \\
\hline Isezuo, 2003 [47] & Ghana & Hypertensive HF & 107 & $53.6 \pm 12.1$ & 52 & \\
\hline Sultana, 2010 [48] & Pakistan & Hypertensive HF & 500 & $>30$ & 69 & 345 \\
\hline
\end{tabular}

Despite the existence of many different types of arrhythmias based on ECG findings, the most evaluated type among HF patients in the included studies is AF. The three others are ventricular premature contractions, ventricular tachycardia, and sinus tachycardia. There was no sufficient data on other less prevalent types of arrhythmias, which the studies commented as a potential cause of unfavorable prognosis during the discussion of the clinical management of HF patients. The study aim and data from the included HF studies strongly suggest that arrhythmias do not form an original objective of HF studies but a secondary or a tertiary purpose.

\section{Arrhythmias}

The ECG is recommended as an essential initial test in HF patients and the most common diagnostic tool for arrhythmias in these patients. The presence of arrhythmias in HF has important clinical implications because of their association with an unfavorable prognosis and diminished efficacy of guideline-directed HF regimens. These patients often require adjunctive antiarrhythmic therapy to maximize the overall therapeutic efficacy of HF regimens. Despite the deleterious effect of arrhythmias in HF patients, they remain an understudied manifestation of HF in both the analysis of clinical registries and HF clinical trials. Studies evaluating arrhythmias in HF patients as the primary objective are conspicuously lacking, with a majority of them only mentioning arrhythmias as a part of patients' clinical features during the index admission. The main reason for the lack of original studies on arrhythmias based on ECG findings may be that the recommended diagnostic use of ECG by both the ESC [12] and ACCF/AHA [13] is preselecting patients for echocardiographic evaluation of the cardiac structure and function in which the detection of arrhythmias is one of the functions. Despite a paucity of original studies on arrhythmias in HF patients, AF remains the most studied arrhythmia followed by ventricular premature contractions (VPC), ventricular tachycardia (VT), and sinus tachycardia. A few studies evaluating clinical management of $\mathrm{HF}$ also mention other less prevalent types of arrhythmias, but the provided data was insufficient to support a pooled analysis.

\section{Supraventricular arrhythmias}

Supraventricular arrhythmias are the most studied form of cardiac arrhythmias. They arise from above the AV node and AF, atrial flutter (Af), and paroxysmal supraventricular tachycardia. Of the three, AF is the most studied supraventricular arrhythmia. Current evidence implicates a marked improvement in longevity and reduction in the overall cardiovascular mortality with the increasing epidemic of comorbid HF and AF. The present findings support the prevalence of AF in HF patients. All the 11 studies analyzing registry data reported the absolute numbers of HF patients with AF and/or atrial flutter in patients in their index presentation. However, the HF registries did not 
discriminate types of HF. They included all types of HF, ranging from HFrEF, HFpEF and HFmEF, systolic HF, hypertensive HF, thyrotoxic $\mathrm{HF}$, and ischemic HF. In a pooled analysis of data from all the 11 registries [16-26], almost a third $(91,423 / 292,927)$ presented with AF on ECG, translating into an event rate (ER) of $32.7 \%$ (95\% CI: $31.1 \%$ to $34.3 \%$, Figure 1). Pooled analysis of the $22 \mathrm{HF}$ studies [27-48], including four registries that provided AF data on different HF types $[18,23,25,26]$, gave a similar event rate. ECG detected AF in 48,075 out of 147,212 HF patients translating into an event rate of $32.7 \%$ (95\% CI: $32.5 \%$ to $33.0 \%$, Figure 2 ).

Further analysis examined the prevalence of AF in different $\mathrm{HF}$ types. The included registries and studies examined 9 types of $\mathrm{HF}-$ HFmEF [25], HFpEF [25,35], HFrEF [18,23,25,32,33,35-40], high output HF [23], hypertensive HF [18,23,26,48], ischemic HF [34,41], right HF [18,23], systolic HF [42-46], and thyrotoxic HF [27-31]. The prevalence of AF across these nine HF types varied significantly. Hypertensive HF had the highest event rate of AF (46.5\%) followed by HFrEF (40.3\%), right HF (37.9\%), HFpEF (34.0\%), systolic HF (31.9\%) and thyrotoxic HF had the least event rate $(6.7 \%)$ followed by high output HF (19.0\%), ischemic HF (23.8\%) AND HFmEF (28.0\%) (Table $3)$.

Consistent with the findings of the present meta-analysis, the bulk of studies reporting ECG findings of arrhythmias among HF patients have almost exclusively focused on AF. Three reasons have considerably influenced the disproportionate focus on AF - high prevalence, unfavorable prognosis, and a refocusing of cardiovascular care. The high prevalence of HF in the general population and HF patients is well documented. AF is the most frequently encountered cardiac arrhythmia in clinical practice and accounts for up to a third of admission due to cardiac rhythm disturbances. Over the past two decades, hospitalization for AF has increased by two thirds. The reasons behind the increase include an aging population, rising prevalence of chronic diseases, and an increase in clinical monitoring [8].

The prevalence of AF is not only high but also expected to increase in the coming decades. The Anticoagulation and Risk Factors in Atrial Fibrillation (ATRIA) study projected that AF prevalence would increase by 2.5 times by the year 2050, affecting about 5.6 million Americans, mostly driven by the improved longevity [49]. The incidence of AF is projected to double over the next two decades, with expectations of 120 to 215 thousand new cases annually by 2030 in Europe alone [50-52]. Rates of HF in a global AF registry were paroxysmal (33\%), persistent (44\%), and permanent AF (56\%) [53]. The prevalence of AF reported in earlier HF series ranged between $13 \%$ and $27 \%$ [54-58]. In the Framingham Heart Study, 1,470 participants developed either de novo AF or HF between 1948 and 1995, or 26\% of them developed both $\mathrm{AF}$ and HF [59]. The prevalence of AF in HF patients also increases with the severity of HF, which ranges from $5 \%$ in mild HF to $26 \%$ in moderate $\mathrm{HF}$ and up to $50 \%$ in patients with severe HF [60].

AF in Heart Failure - Event Rate and $95 \% \mathrm{Cl}$

\begin{tabular}{|c|c|c|c|c|c|c|c|c|}
\hline \multirow[t]{2}{*}{ Study name } & \multirow{2}{*}{$\begin{array}{c}\text { Events/Total } \\
\text { Total }\end{array}$} & \multicolumn{3}{|c|}{ Statistics for each study } & \multicolumn{4}{|c|}{ Event rate and $95 \% \mathrm{CI}$} \\
\hline & & $\begin{array}{c}\text { Event } \\
\text { rate }\end{array}$ & $\begin{array}{c}\text { Lower } \\
\text { limit }\end{array}$ & $\begin{array}{c}\text { Upper } \\
\text { limit }\end{array}$ & & & & \\
\hline ADHERE [16] & $32670 / 105388$ & 0.310 & 0.307 & 0.313 & & & & \\
\hline OPTIMIZ-HF [17] & 14970 / 48612 & 0.308 & 0.304 & 0.312 & & & & \\
\hline EHFS II [18] & $1385 / 3580$ & 0.387 & 0.371 & 0.403 & & & & \\
\hline EFICA [19] & $145 / 581$ & 0.250 & 0.216 & 0.286 & & & & \\
\hline ESC-HF Pilot [20] & $1791 / 5118$ & 0.350 & 0.337 & 0.363 & & & & \\
\hline RO-AHFS [21] & 1419 / 3224 & 0.440 & 0.423 & 0.457 & & & & \\
\hline ALARM-HF [22] & $1209 / 4953$ & 0.244 & 0.232 & 0.256 & & & & \\
\hline AHEAD [23] & $1101 / 4153$ & 0.265 & 0.252 & 0.279 & & & & \\
\hline In-HF Outcome [24] & $699 / 1855$ & 0.377 & 0.355 & 0.399 & & & & \\
\hline GWTG-HF [25] & $34293 / 110621$ & 0.310 & 0.307 & 0.313 & & & & \\
\hline \multirow[t]{4}{*}{ ATTEND [26] } & $1741 / 4842$ & 0.360 & 0.346 & 0.373 & & & & \\
\hline & $91423 / 292927$ & 0.327 & 0.311 & 0.343 & & & 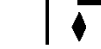 & \\
\hline & & & & & -0.50 & -0.25 & 0.25 & 0.50 \\
\hline & & & & & \multicolumn{2}{|c|}{ Favours No AF } & avours A & \\
\hline
\end{tabular}

Heterogeinity: $Q=1015.01 ; \operatorname{df}(Q)=8(p=0.000)$; Inconsistency $(I-S q u a r e d)=99.21 \%$

Figure 1. Event rate of atrial fibrillation in heart failure based on registry data

Table 3. Atrial fibrillation event rate in heart failure types

\begin{tabular}{|c|c|c|c|c|c|}
\hline HF Type & Positive Cases & Total Cases & Event Rate (\%) & $95 \%$ CI & Studies \\
\hline Hypertensive HF & 1,130 & 2,401 & 46.5 & 44.4 to 48.6 & $18,23,26,48$ \\
\hline HFrEF & 11,197 & 27,504 & 40.3 & 39.7 to 41.0 & $18,23,25,32,33,35-40$ \\
\hline Right HF & 96 & 269 & 37.9 & 31.8 to 44.5 & 18,23 \\
\hline HFpEF & 13,730 & 40,425 & 34.0 & 33.5 to 34.4 & 25,35 \\
\hline Systolic HF & 6,227 & 19,705 & 31.9 & 31.3 to 32.6 & $42-46$ \\
\hline HFmEF & 15,423 & 55,083 & 28.0 & 27.6 to 28.4 & 25 \\
\hline Ischemic HF & 191 & 803 & 23.8 & 21.0 to 26.9 & 34,41 \\
\hline High Output HF & 34 & 179 & 19.0 & 13.9 to 25.4 & 23 \\
\hline Thyrotoxic HF & 47 & 753 & 6.7 & 5.1 to 8.8 & $27-31$ \\
\hline
\end{tabular}


Atrial Fibrillation in Different HF Types: Event Rate and 95\% Cl

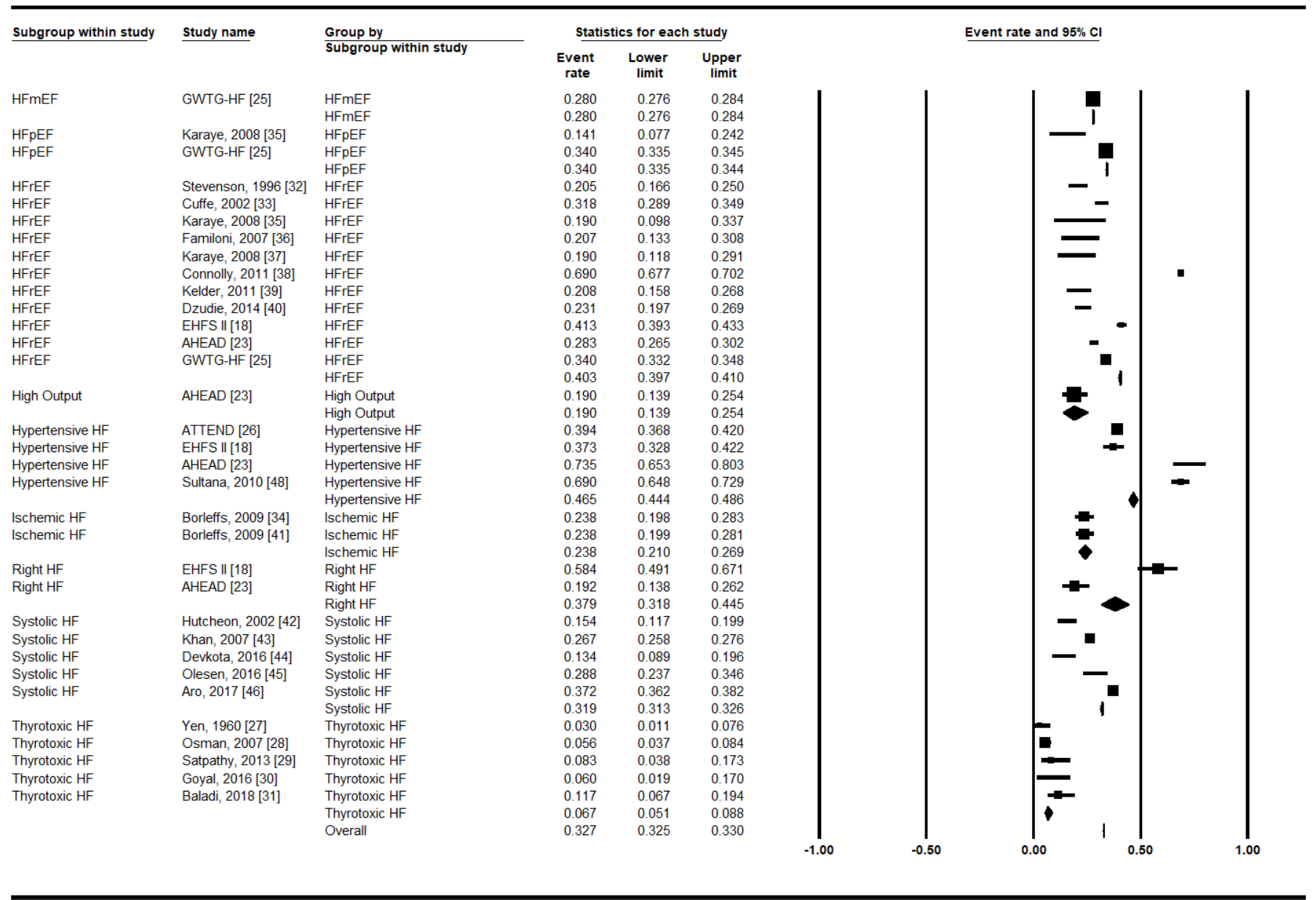

Figure 2. Event rate and $95 \% \mathrm{CI}$ of atrial fibrillation in different types of $\mathrm{HF}$

The presence of AF in HF patients is associated with an unfavorable prognosis and a higher risk of death, and thus a reason for a disproportionate study interest. The causative relationship between AF and HF has not been entirely determined. Still, the presence of conventional risk factors such as age, smoking, hypertension, diabetes, renal impairment, and obesity as well as valvular, ischemic or nonischemic structural heart disease increases the risk of developing both AF and HF. These factors cause myocardial cellular and extracellular alterations, electrophysiological, and neurohormonal changes that may combine, resulting in an environment that predisposes the heart to both $\mathrm{HF}$ and $\mathrm{AF}[7,8]$. AF is both a cause and a consequence of HF with complex interactions that result in systolic and diastolic dysfunction absent in sinus rhythm. On the one hand, AF is associated with a threefold increase in the risk of HF, and on the other hand, structural and neurohormonal changes in HF can result in the development and progression of $\mathrm{AF}[60,61]$.

AF can be a consequence of HF. In HF patients, neurohormonal imbalance and activation of the renin-angiotensin-aldosterone system (RAAS) may result in maladaptive physiological alterations, including elevated filling pressures and afterload. These alterations cause an increase in left atrial dilation and fibrosis, contributing to the development of conduction abnormalities and facilitating the initiation and maintenance of AF [62-66]. The RAAS may also have a direct contribution to pro-arrhythmic remodeling with angiotensin II, leading to atrial fibrosis and anisotropic conduction [67]. HF patients may also exhibit altered calcium handling and overload that can lead to after depolarization and arrhythmia [68].

AF can be the cause of HF. A number of established mechanisms may be responsible for the development of HF in patients with AF. The loss of atrial systole in AF may impair LV filling resulting in a decrease in cardiac output by up to $25 \%$, particularly in patients with diastolic dysfunction [69]. Irregular and/pr rapid ventricular conduction in AF patients can result in LV dysfunction, and in some patients, can lead to the development of tachycardia-induced cardiomyopathy $[69,70]$. Restoring sinus rhythm increases stroke volume and LV emptying prior to the improvement of the contractile function, and may explain why some HF patients have rapid hemodynamic improvement with cardioversion [71].

The interest in AF in HF patients also stems from its dramatic impact on healthcare to require a refocus on cardiac care. Given the unfavorable prognosis and poor outcomes associated with the presence of AF in HF patients, finding effective regimens for these patients is critical but also challenging. Treatment that may be effective on one condition alone may have efficacy or safety concerns in the presence of both AF and HF. At present, the management of comorbid HF and AF 
focuses on particular therapeutic aspects backed by evidence-based in one or both conditions [7]. Researchers have begun to evaluate whether treatment efficacy differs in patients with concomitant disease, but currently, the data is limited.

The CAN-TREAT HFrEF + AF algorithm (Cardioversion if compromised; Anticoagulation unless contraindication; Normalize fluid balance; Target initial heart rate $<110 \mathrm{bpm}$; RAAS modification; Early consideration of rhythm control; Advanced HF therapies; Treatment of other CV diseases) distinguishes the management of these patients from HF patients with sinus rhythm [8]. The CANTREAT HFrEF + AF algorithm recommends that the presence of hemodynamic instability in $\mathrm{AF}+\mathrm{HF}$ patients require treatment with urgent cardioversion. Anticoagulation is useful in the prevention of thromboembolic events and stroke, and diuretic therapy to normalize fluid balance and reduce HF symptoms. Subsequent therapy should focus on the initial heart rate $<110 \mathrm{bpm}$ and initiate RAAS antagonism. Early rhythm control in patients with symptoms refractory to rate control, the consideration of advanced HF regimens are recommended, such as cardiac resynchronization therapy, with aggressive treatment of other concomitant cardiovascular diseases particular ischemia and hypertension.

\section{Ventricular arrhythmias}

Besides supraventricular arrhythmias, the other most commonly studied cardiac arrhythmias are ventricular arrhythmias, which arise from the AV junction or within the AV node itself and include ventricular tachycardia (VT) and ventricular fibrillation (VF). The present meta-analysis found ventricular arrhythmias in 272 out of 973 HF patients in six studies [27-29,31,35,44] translating into an event rate of $32.0 \%$ (95\% CI: $12.2 \%$ to $61.3 \%$; Figure 3). Among ventricular arrhythmias, VT was the most prevalent, reported in 9,061 out of $114,035 \mathrm{HF}$ patients in four large HF registries $[16,19,21,26]$ translating into an event rate of 5.6\% (95\% CI: 3.9\% to 7.9\%; Figure 4). Further pooled analysis of the prevalence of VT in different HF types was not possible since it was only reported in one registry [18] and one study [48] in HFrEF, hypertensive, and right HF patients. In the two studies, VT was more prevalent in hypertensive HF $(19.2 \%$; 95\% CI: $16.0 \%$ to $22.9 \%$ ) but less prevalent in HFrEF (3.7\%; 95\% CI: $3.0 \%$ to $4.6 \%)$ and right $\operatorname{HF}(2.7 \%$; $95 \%$ CI: $0.9 \%$ to $7.9 \%)$. Ventricular premature contractions (VPC) have been reported in six studies in HFrEF patients with an event rate of $13.3 \%$ (95\% CI: $11.4 \%$ to $15.4 \%$ ) [27,29,35,41,44,48] (Figure 5).

Sinus Tachycardia in Differrent HF Types: Event Rate and 95\% Cl



Figure 3. Event rate of sinus tachycardia in heart failure

VT in Heart Failure: Event Rate and $95 \% \mathrm{Cl}$

\begin{tabular}{|c|c|c|c|c|}
\hline \multirow[t]{2}{*}{ Study name } & \multirow{2}{*}{$\begin{array}{c}\text { Events/Total } \\
\text { Total }\end{array}$} & \multicolumn{3}{|c|}{ Statistics for each study } \\
\hline & & $\begin{array}{c}\text { Event } \\
\text { rate }\end{array}$ & $\begin{array}{c}\text { Lower } \\
\text { limit }\end{array}$ & limit \\
\hline $\mathrm{DHE}$ & $8431 / 105388$ & 0.080 & 0.078 & 0.082 \\
\hline EFICA & $12 /$ & 0.021 & .0 & 0.036 \\
\hline २०-Al & 1 & 6 & 0.0 & 0.043 \\
\hline II I I & & & & 0.11 \\
\hline & $9061 / 1140$ & 0.056 & 0.039 & 0.07 \\
\hline
\end{tabular}

Event rate and $95 \% \mathrm{CI}$


Favours No VT Favours VT

Heterogeneity: $Q=140.176 ; \operatorname{df}(Q)=3(p=0.000) ;$ Inconsistence $($-Squared $)=97.86 \%$

Figure 4. Event rate of ventricular tachycardia in heart failure based on registry data 
Ventricular Premature Contractions in Differrent HF Types: Event Rate and 95\% Cl

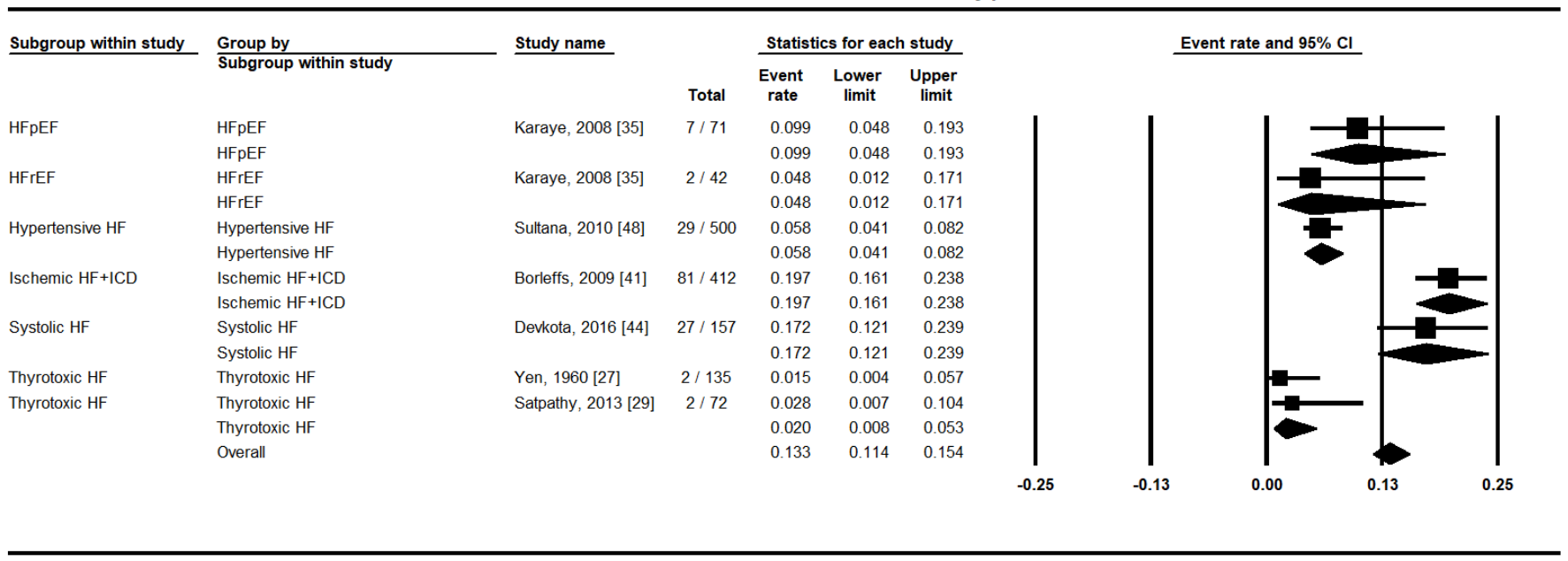

Figure 5. Event rate of ventricular premature contraction in HF

Our present findings reveal that studies evaluating VT among HF patients are lacking. The study of ventricular arrhythmias is complicated by its broad-spectrum, which ranges from isolated and asymptomatic ventricular ectopy on ECG to fatal VF. Together with VA's high spontaneous variability, the assessment of the prevalence and incidence of Vas in the HF population becomes extremely difficult, explaining the paucity of studies on VA in HF. However, the VA may be more common in patients with ischemic HF and severely reduced LVEF. Typically, discussions on the risk of VA in HF mainly refer to HFrEF patients.

Ventricular arrhythmias are more prevalent in hypertensive HF relative to other forms of HF. Hypertension has two significant consequences on the heart, LV hypertrophy and morphological and functional alterations of the coronary macro and microvessels. The two consequences are responsible for three types of cardiac complications, LV dysfunction, myocardial ischemia, and electrical instability together involved in the initiation and maintenance of ventricular arrhythmias in hypertensive HF. A simple or complex ventricular extrasystole often involving a re-entry circuit in the presence of concomitant LV usually triggers VAs. More often, asymmetric septal and eccentric hypertrophy can lead to VAs than concentric LV hypertrophy [48].

The occurrence of VA appears to be lower in studies evaluating the HFpEF population. The low prevalence of VA in HFpEF has been supported by large-scale clinical trials evaluating treatment options for HFpEF patients. Irbesartan in Heart Failure with Preserved Ejection Fraction (I-Preserve) [72], Digitalis Investigation Group Preserved Ejection Fraction (DIG-PEF) [73], Candesartan in Heart failure Assessment of Reduction of Mortality and morbidity (CHARMPreserved) [74], and Perindopril in Elderly People with Chronic Heart Failure (PEP-CHF) [75] have reported low rates of ICD (0.3\% to $0.8 \%)$ and antiarrhythmic drug use ( $8.7 \%$ to $10 \%)$.

Despite the low prevalence of VA in HF, they are generally associated with an increased risk of death. Ventricular premature beats or non-sustained ventricular tachycardia (NSVT) and VT/VF are part of a broader definition of VA in HF. However, a large clinical gap exists between VPC/NSVT and sustained VT/VF that cause sudden cardiac death (SCD). Although VAs, in particular, VPC and NSVT, are frequent in HF, it has not been concluded that they are necessarily associated with an increased risk of SCD. However, a posthoc analysis of the Sudden Cardiac Death in Heart Failure Trial (SCD-HeFT) trial demonstrated an association between rapid rate NSVT in HF patients with ICD use and all-cause mortality [76].

\section{Clinical implications}

The precise knowledge of the prevalence of AF in different HF types has important clinical implications, especially in guiding initial diagnostic tests and treatment in this population. The onset of $\mathrm{AF}$ may worsen signs and symptoms of HF reflected by a peak oxygen consumption, which is higher at the anaerobic threshold but lower at the overall peak in permanent AF patients. In AF patients, the development of $\mathrm{HF}$ increases the risk of mortality, which is higher in women (hazard ratio [HR] 3.1) compared to men (HR: 2.7). Similarly, the development of $\mathrm{AF}$ in $\mathrm{HF}$ is also associated with an increased risk of mortality (women HR: 2.7 and men HR: 1.6) [59]. The relative contribution of $\mathrm{AF}$ and HF to the clinical status of many patients is challenging to determine because AF can be both a cause and consequence of HF. The co-existence of $\mathrm{AF}$ and $\mathrm{HF}$ is the most common underlying cardiac disorder in patients presenting with stroke [77]. About $50 \%$ of $\mathrm{HF}$ patients with stroke have concomitant $\mathrm{AF}$, and $82 \%$ of all strokes are cardioembolic [78].

Studies also did not report the prevalence of different types of AF in HF patients, which would have been clinically relevant for prognostication because they confer various risks of stroke. For instance, non-valvular AF confers a five-fold increase in the risk of ischemic stroke and systemic embolism compared with HF patients in sinus rhythm. The risk further increases by $\sim 40 \%$ in the presence of HF. Similarly, HF confers a 17 -fold increase in the risk of stroke within the first month of diagnosis, and the presence of AF increases the risk by 2-3 fold [5]. Many patients in sinus rhythm may also have silent AF episodes with a similar or increased risk of stroke as symptomatic AF [79-81]. The risk of stroke in HFpEF may be the same or even higher than in HFrEF [82-84]. About one-third of HF patients have AF, which may occur without specific symptoms, although it remains a leading cause of stroke and deterioration of HF symptoms.

The knowledge of the prevalence of VAs in HF patients also has important clinical implications. They are a leading cause of SCD or 
resuscitated SCD in HF patients. About $50 \%$ of all deaths in advanced $\mathrm{HF}$ are $\mathrm{SCD}$, and the current assumption is that a significant proportion is the consequence of VT/VF [85]. The severity of HF correlates with the percentage of SCD, although the absolute risk of VA and SCD probably continues to increase. Similarly, chronic HF doubles the risk of subsequent severe VAs in the Triggers of Ventricular Arrhythmias (TOVA) study of 1,140 ICD implanted patients with $44 \%$ having HF at baseline. The risk of ICD discharger for VT/VF at 12 months is higher in HF Patients (12.1\%) compared to those without HF (6.5\%) [86]. In a large outpatient registry of HF, of which $29 \%$ with a history of VT and LBBB had increased risk of mortality (HR: 1.70) and SCD (HR: 1.58) over 12 months of follow up period [87]. The study also reported that VT was an independent predictor of total mortality (HR: 1.76) and SCD (HR: 1.96) at 12 months. In the SCD-HeFT trial that randomized NYHA II or III patients to ICD, antiarrhythmic drug (amiodarone) or placebo, deaths occurred to $22.0 \%$ ICD receptions, $28.4 \%$ to patients on the antiarrhythmic medication, and $28.8 \%$ to patients on placebo. Cardiac mortality resulting from SCD due to VTs occurred only in $4.5 \%$ in the ICD group, $8.9 \%$ on the antiarrhythmic drug, and $11.2 \%$ on patients on placebo. The mode of death analysis of SCD-HeFT indicated that ICD-related reduction in mortality was almost all due to protection from SCD presumed to originate from VTs.

\section{Conclusion}

Arrhythmias are common in all forms of heart failure (HF). Arrhythmias can be categorized as supraventricular (or atrial) or ventricular based on the point of origin. They are prognostically significant since they confer additional risk of morbidity, hospitalization, and mortality, as well as have an important bearing on the management of these patients. Despite their therapeutic relevance, they remain an understudied pathology of HF partly because of the lack of uniformity in the definition of HF coupled with the transient nature of arrhythmias. Although ECG is recommended as an initial test for all patients suspected with HF, and it is the most common method used in the detection of arrhythmias, its use in the detection of arrhythmias is not routine. Its main use is pre-selection patients for echocardiography based on the presence of ECG abnormalities. However, a normal ECG does not also exclude HF. In the present analysis, arrhythmias occur in about a third of HF patients. Atrial fibrillation and ventricular tachycardia are the most researched types of arrhythmias because of their association with increased risk of thromboembolic events and stroke and sudden cardiac death, respectively. The prevalence of different types of arrhythmias in different HF types remains unclear because of the lack of data to support pooled analyses. Based on the present findings, clinical management of HF should take into account the elevated risk of arrhythmias in HF patients. There is also a need for more studies to determine the overall prevalence of arrhythmias in HF patients, including the prevalence of specific types of arrhythmias in particular forms of HF to guide diagnosis and management.

\section{References}

1. Williams H (2009) Heart disease (8) Arrhythmias: Part 1. Pharmaceutical Journal 271: 368-370.

2. Parmley WW, Chatterjee K (1986) Congestive heart failure and arrhythmias: an overview. Am J Cardiol 57: B34-B37. [Crossref]

3. Xiao YF (2011) Cardiac arrhythmia and heart failure: From bench to bedside. J Geriatr Cardiol 8: 131-132. [Crossref]

4. De Ferrari GM, Tavazzi L (1999) The role of arrhythmias in the progression of heart failure. Eur J Heart Fail 1: 35-40. [Crossref]
5. Lip GY, Heinzel FR, Gaita F, Juanatey JR, Le Heuzey JY, et al. (2015) European heart rhythm association/heart failure association joint consensus document on arrhythmias in heart failure, endorsed by the Heart rhythm society and the Asia Pacific heart rhythm society. Europace 18: 12-36. [Crossref]

6. Masarone D, Limongelli G, Rubino M, Valente F, Vastarella R, et al. (2017) Management of arrhythmias in heart failure. J Cardiovasc Dev Dis 4: 1-20. [Crossref]

7. Kotecha D, Piccini JP (2015) Atrial fibrillation in heart failure: what should we do? Eur Heart J 36: 3250-3257. [Crossref]

8. Anter E., Jessup M, Callans DJ (2009) Atrial fibrillation and heart failure: treatment considerations for a dual epidemic. Circulation 119: 2516-2525. [Crossref]

9. Olsson LG, Swedberg K, Ducharme A, Granger CB, Michelson EL, et al. (2006) Atrial fibrillation and risk of clinical events in chronic heart failure with and withou left ventricular systolic dysfunction: results from the Candesartan in Heart failureAssessment of Reduction in Mortality and morbidity (CHARM) program. $J$ Am Coll Cardiol 47: 1997-2004. [Crossref]

10. Luu M, Stevenson WG, Stevenson LW, Baron K, Walden J (1989) Diverse mechanisms of unexpected cardiac arrest in advanced heart failure. Circulation 80: 1675-1680. [Crossref]

11. Digitalis Investigation Group (1997) The effect of digoxin on mortality and morbidity in patients with heart failure. $N$ Engl J Med 336: 525-533. [Crossref]

12. Ponikowski P, Voors AA, Anker SD, Bueno H, Cleland JG, et al. (2016) 2016 ESC Guidelines for the diagnosis and treatment of acute and chronic heart failure: The Task Force for the diagnosis and treatment of acute and chronic heart failure of the European Society of Cardiology (ESC) Developed with the special contribution of the Heart Failure Association (HFA) of the ESC. Eur Heart J 37: 2129-2200. [Crossref]

13. Yancy CW, Jessup M, Bozkurt B, Butler J, Casey DE, et al. (2013) 2013 ACCF/AHA guideline for the management of heart failure: a report of the American College of Cardiology Foundation/American Heart Association Task Force on Practice Guidelines. $J$ Am Coll Cardiol 62: e147-e239. [Crossref]

14. Moher D, Liberati A, Tetzlaff J, Altman DG, Prisma Group (2009) Preferred reporting items for systematic reviews and meta-analyses: the PRISMA statement. PLoS Medicine 6: e1000097. [Crossref]

15. Davie AP, Francis CM, Love MP, Caruan L, Starkey IR, et al. (1996) Value of the electrocardiogram in identifying heart failure due to left ventricular systolic dysfunction. BMJ 312: 222. [Crossref]

16. Adams Jr KF, Fonarow GC, Emerman CL, LeJemtel TH, Costanzo MR, et al. (2005) Characteristics and outcomes of patients hospitalized for heart failure in the United States: rationale, design, and preliminary observations from the first 100,000 cases in the Acute Decompensated Heart Failure National Registry (ADHERE). Am Heart $J$ 149: 209-216. [Crossref]

17. Gheorghiade M, Abraham WT, Albert NM, Greenberg BH, O'Connor CM, et al. (2006) Systolic blood pressure at admission, clinical characteristics, and outcomes in patients hospitalized with acute heart failure. Jama 296: 2217-2226. [Crossref]

18. Nieminen MS, Brutsaert D, Dickstein K, Drexler H, Follath F, et al. (2006) EuroHeart Failure Survey II (EHFS II): a survey on hospitalized acute heart failure patients: description of population. Eur Heart J 27: 2725-2736. [Crossref]

19. Zannad F, Mebazaa A, Juillière Y, Cohen Solal A, Guize L, et al. (2006) Clinical profile, contemporary management and oneyear mortality in patients with severe acute heart failure syndromes: The EFICA study. Eur J Heart Fail 8: 697-705. [Crossref]

20. Maggioni AP, Dahlström U, Filippatos G, Chioncel O, Leiro MC, et al. (2010) EURObservational Research Programme: the Heart Failure Pilot Survey (ESC-HF Pilot). Eur J Heart Fail 12(10): 1076-1084. [Crossref]

21. Chioncel O, Vinereanu D, Datcu M, Ionescu DD, Capalneanu R, et al. (2011) The Romanian acute heart failure syndromes (RO-AHFS) registry. Am Heart J 162: 142153. [Crossref]

22. Follath F, Yilmaz MB, Delgado JF, Parissis JT, Porcher R., et al. (2011) Clinical presentation, management, and outcomes in the acute heart failure global survey of standard treatment (ALARM-HF). Intensive Cara Med 37: 619-626. [Crossref]

23. Spinar J, Parenica J, Vitovec J, Widimsky P, Linhart A, et al. (2011) Baseline characteristics and hospital mortality in the Acute Heart Failure Database (AHEAD) Main registry. Crit Care 15: 1-13. [Crossref]

24. Oliva F, Mortara A, Cacciatore G, Chinaglia A, Di Lenarda A, et al. (2012) Acute heart failure patient profiles, management, and in-hospital outcome: results of the Italian Registry on Heart Failure Outcome. Eur J Heart Fail 14: 1208-1217. [Crossref] 
25. Steinberg BA, Zhao X, Heidenreich PA, Peterson ED, Bhatt DL, Cannon CP, et al. (2012) Trends in patients hospitalized with heart failure and preserved left ventricular ejection fraction: prevalence, therapies, and outcomes. Circulation 126: 65-75. [Crossref]

26. Sato N, Kajimoto K, Keida T, Mizuno M, Minami Y, et al. (2013) Clinical features and outcome in hospitalized heart failure in Japan (from the ATTEND Registry). Circ J 77: 944-951. [Crossref]

27. Yen SC (1960) The electrocardiogram in thyrotoxicosis. Folia Endocrinologica Japonica 36: 56-65.

28. Osman F, Franklyn JA, Holder RL, Sheppard MC, Gammage MD (2007) Cardiovascular manifestations of hyperthyroidism before and after antithyroid therapy: a matched case-control study. J Am Coll Cardiol 49: 71-81. [Crossref]

29. Satpathy PK, Diggikar PM, Sachdeva V, Laddha M, Agarwal A, et al. (2013) Lipid profile and electrocardiographic changes in thyroid dysfunction. Medical Journal of $\mathrm{Dr}$. DY Patil University 6: 250-253. [Crossref]

30. Goyal S, Goyal V (2016) A study of electrocardiographic changes in thyroid disorders. International Journal of Medical Research and Review 4: 486-490. [Crossref]

31. Baladi IH, Rai AA, Ahmed SM (2018) ECG changes in patients with primary hyperthyroidism. Pan Afr Med J 30: 246. [Crossref]

32. Stevenson WG, Stevenson LW, Middlekauff H, Fonarow GC, Hamilton MA, et al. (1996) Improving survival for patients with atrial fibrillation and advanced hear failure. J Am Coll Cardiol 28: 1458-1463. [Crossref]

33. Cuffe MS, Califf RM, Adams Jr, KF, BenzaR, Bourge R, et al. (2002) Short-term intravenous milrinone for acute exacerbation of chronic heart failure: a randomized controlled trial. Jama 287: 1541-1547. [Crossref]

34. Familoni OB, Olunuga TO, Olufemi BW (2007) A clinical study of pattern and factors affecting outcome in Nigerian patients with advanced heart failure. Cardiovasc $J$ Afr 18: 308-311. [Crossref]

35. Ostor E, Jensen G, Nyboe J, Hansen AT (1981) Electrocardiographic findings and their association with mortality in the Copenhagen City Heart Study. Eur Heart J 2: 317 328. [Crossref]

36. Karaye KM, Sani, MU (2008) Electrocardiographic abnormalities in patients with heart failure. Cardiovasc J Afr 19: 22-25. [Crossref]

37. Karaye KM, Sani MU (2008) Factors associated with poor prognosis among patients admitted with heart failure in a Nigerian tertiary medical centre: a cross-sectional study. BMC Cardiovasc Disord 8: 1-8. [Crossref]

38. Connolly SJ, Eikelboom J, Joyner C, Diener HC, Hart R, et al. 2011) Apixaban in patients with atrial fibrillation. $N$ Engl J Med 364: 806-817. [Crossref]

39. Kelder JC, Cramer MJ, van Wijngaarden J, van Tooren R, Mosterd A, et al. (2011) The diagnostic value of physical examination and additional testing in primary care patients with suspected heart failure. Circulation 124: 2865-2873. [Crossref]

40. Dzudie A, Milo O, Edwards C, Cotter G, Davison BA, et al. (2014) Prognostic significance of ECG abnormalities for mortality risk in acute heart failure: insight from the Sub-Saharan Africa Survey of Heart Failure (THESUS-HF). J Card Fail 20: 45-52.

41. Borleffs CJW, Scherptong RW, Man SC, van Welsenes GH, Bax JJ, et al. (2009) Predicting ventricular arrhythmias in patients with ischemic heart disease: clinical application of the ECG-derived QRS-T angle. Circ Arrhythm Electrophysiol 2: 548554. [Crossref]

42. Hutcheon SD, Gillespie ND, Struthers AD, McMurdo ME (2002) B-type natriuretic peptide in the diagnosis of cardiac disease in elderly day hospital patients. Age Ageing 31: 295-301. [Crossref]

43. Khan NK, Goode KM, Cleland JG, Rigby AS, Freemantle N, et al. (2007) Prevalence of ECG abnormalities in an international survey of patients with suspected or confirmed heart failure at death or discharge. Eur J Heart Fail 9: 491-501. [Crossref]

44. Devkota A, Bakhit A, Dufresne AO, Parajuli P, et al. (2016) Arrhythmias and electrocardiographic changes in systolic heart failure. $N$ Am J Med Sci 8: 171-174. [Crossref]

45. Olesen LL, Andersen A (2016) ECG as a first step in the detection of left ventricular systolic dysfunction in the elderly. ESC Heart Failure 3: 44-52. [Crossref]

46. Aro AL, Reinier K, Uy-Evanado A, Rusinaru C, Ju, J, et al. (2017) Prediction of moderate left ventricular systolic dysfunction from the 12-lead electrocardiogram. Eur Heart J 38: 902-909.

47. Isezuo AS, Omotoso AB, Araoye MA, Carr J Corrah T (2003) Determinants of prognosis among black Africans with hypertensive heart failure. Afr J Med Med Sci 32: 143-149. [Crossref]
48. Sultana R, Sultan N, Rashid A, Rasheed SZ, Isha M, et al. (2010) Cardiac arrhythmias and left ventricular hypertrophy in systemic hypertension. J Ayub Med Coll Abbottabad 22: 155-158. [Crossref]

49. Go AS, Hylek EM, Phillips KA, Chang Y, Henault LE, et al. (2001) Prevalence of diagnosed atrial fibrillation in adults: national implications for rhythm management and stroke prevention: the Anticoagulation and Risk Factors in Atrial Fibrillation (ATRIA) Study. JAMA 285: 2370-2375. [Crossref]

50. Chugh SS, Havmoeller R, Narayanan K, Singh D, Rienstra M, et al. (2014) Worldwide epidemiology of atrial fibrillation: a Global Burden of Disease 2010 Study. Circulation 129: 837-847. [Crossref]

51. Colilla S, Crow A, Petkun W, Singer DE, Simon T, et al. (2013) Estimates of current and future incidence and prevalence of atrial fibrillation in the U.S. adult population. Am J Cardiol 112: 1142-1147. [Crossref]

52. Zoni-Berisso M, Lercari F, Carazza T, Domenicucci S (2014) Epidemiology of atrial fibrillation: European perspective. Clin Epidemiol 6: 213-220. [Crossref]

53. Chiang CE, Naditch-Brule L, Murin J, Goethals M, Inoue H, et al. (2012) Distribution and risk profile of paroxysmal, persistent, and permanent atrial fibrillation in routine clinical practice: insight from the reallife global survey evaluating patients with atria fibrillation international registry. Circ Arrhythm Electrophysiol 5: 632-639. [Crossref]

54. Middlekauff HR, Stevenson WG, Stevenson LW (1991) Prognostic significance of atrial fibrillation in advanced heart failure: a study of 390 patients. Circulation 84: 40-48. [Crossref]

55. Carson PE, Johnson GR, Dunkman WB, Fletcher RD, Farrell L, et al. (1993) The influence of atrial fibrillation on prognosis in mild to moderate heart failure: the V-HeFT Studies: the V-HeFT VA Cooperative Studies Group. Circulation 87: VI-102VI-110. [Crossref]

56. Mahoney P, Kimmel S, DeNofrio D, Wahl P, Loh E (1999) Prognostic significance of atrial fibrillation in patients at a tertiary medical center referred for heart transplantation because of severe heart failure. Am J Cardiol 83: 1544-1547. [Crossref]

57. Senni M, Tribouilloy CM, Rodeheffer RJ, Jacobsen SJ, Evans JM, et al. (1998) Congestive heart failure in the community: study of all incident cases in Olmsted County, Minnesota, in 1991.Circulation 98: 2282-2289. [Crossref]

58. Deedwania PC, Singh BN, Ellenbogen K, Fisher S, Fletcher R, et al. (1998) Spontaneous conversion and maintenance of sinus rhythm by amiodarone in patients with heart failure and atrial fibrillation: observations from the Veterans Affairs Congestive Heart Failure Survival Trial of Antiarrhythmic Therapy (CHF-STAT): the Department of Veterans Affairs CHF-STAT Investigators. Circulation 98: 2574-2579. [Crossref]

59. Wang TJ, Larson MG, Levy D, Vasan RS, Leip EP, et al. (2003) Temporal relations of atrial fibrillation and congestive heart failure and their joint influence on mortality: the Framingham Heart Study. Circulation 107: 2920-2925. [Crossref]

60. Maisel WH, Stevenson LW (2003) Atrial fibrillation in heart failure: epidemiology, pathophysiology, and rationale for therapy. Am J Cardiol 91: 2D-8D. [Crossref]

61. Stewart S, Hart CL, Hole DJ, McMurray JJ (2002) A population-based study of the longterm risks associated with atrial fibrillation: 20-year follow-up of the Renfrew/ Paisley study. Am J Med 113: 359-364. [Crossref]

62. Kalifa J, Jalife J, Zaitsev AV, Bagwe S, Warren M, et al. (2003) Intra-atrial pressure increases rate and organization of waves emanating from the superior pulmonary veins during atrial fibrillation. Circulation 108: 668-671. [Crossref]

63. Lalani GG, Schricker A, Gibson M, Rostamian A, Krummen DE, et al. (2012) Atria conduction slows immediately before the onset of human atrial fibrillation: a bi-atria contact mapping study of transitions to atrial fibrillation. J Am Coll Cardiol 59: 595606. [Crossref]

64. Mills RW, Narayan SM, McCulloch AD (2008). Mechanisms of conduction slowing during myocardial stretch by ventricular volume loading in the rabbit. Am J Physiol Heart Circ Physiol 295: H1270-H1278. [Crossref]

65. Stiles MK, John B, Wong CX, Kuklik P, Brooks AG, et al. (2009) Paroxysmal lone atrial fibrillation is associated with an abnormal atrial substrate: characterizing the 'second factor'. J Am Coll Cardiol 53: 1182-1191. [Crossref]

66. Healey JS, Israel CW, Connolly SJ, Hohnloser SH, Nair GM, et al. (2012) Relevance of electrical remodeling in human atrial fibrillation: results of the asymptomatic atria fibrillation and stroke evaluation in pacemaker patients and the atrial fibrillation reduction atrial pacing trial mechanisms of atrial fibrillation study. Circ Arrhythm Electrophysiol 5: 626-631. [Crossref]

67. Li D, Shinagawa K, Pang L, Leung TK, Cardin S, et al. (2001) Effects of angiotensinconverting enzyme inhibition on the development of the atrial fibrillation substrate in dogs with ventricular tachypacing-induced congestive heart failure. Circulation 104 2608-2614. [Crossref] 
68. Narayan SM, Franz MR, Clopton P, Pruvot EJ, Krummen DE (2011) Repolarization alternans reveals vulnerability to human atrial fibrillation. Circulation 123: 2922-2930. [Crossref]

69. Deedwania PC, Lardizabal JA (2010) Atrial fibrillation in heart failure: a comprehensive review. Am J Med 123: 198-204. [Crossref]

70. Nerheim P, Birger-Botkin S, Piracha L, Olshansky B (2004) Heart failure and sudden death in patients with tachycardia-induced cardiomyopathy and recurrent tachycardia. Circulation 110: 247-252. [Crossref]

71. Raymond RJ, Lee AJ, Messineo FC, Manning WJ, Silverman DI (1998) Cardiac performance early after cardioversion from atrial fibrillation. Am Heart $J$ 136: 435-442. [Crossref]

72. McMurray JJ, Carson PE, Komajda M, McKelvie R, Zile MR, et al. (2008) Heart failure with preserved ejection fraction: clinical characteristics of 4133 patients enrolled in the I-PRESERVE trial. Eur J Heart Fail 10: 149-156. [Crossref]

73. Cleland JG, Tendera M, Adamus J, Freemantle N, Polonski L, et al. (2006) The perindopril in elderly people with chronic heart failure (PEP-CHF) study. Eur Heart $J$ 27: 2338-2345. [Crossref]

74. Ahmed A, Rich MW, Fleg JL, Zile MR, Young JB, et al. (2006) Effects of digoxin on morbidity and mortality in diastolic heart failure: the ancillary digitalis investigation group trial. Circulation 114: 397-403. [Crossref]

75. Yusuf S, Pfeffer MA, Swedberg K, Granger CB, Held P, et al. (2003) Effects of candesartan in patients with chronic heart failure and preserved left-ventricular ejection fraction: the CHARM-Preserved Trial. Lancet 362: 777-781. [Crossref]

76. Chen J, Johnson G, Hellkamp AS, Anderson J, Mark DB, et al. (2013) Rapid-rate non-sustained ventricular tachycardia found on implantable cardioverter defibrillator interrogation: relationship to outcomes in the SCD-HeFT (Sudden Cardiac Death in Heart Failure Trial). J Am Coll Cardiol 61: 2161-2168. [Crossref]

77. Pullicino PM, Halperin JL, Thompson JL (2000) Stroke in patients with heart failure and reduced left ventricular ejection fraction. Neurology 54: 288-294. [Crossref]

78. Vemmos K, Ntaios G, Savvari P, Vemmou AM, Koroboki E, et al. (2012) Stroke aetiology and predictors of outcome in patients with heart failure and acute stroke: a 10-year follow-up study. Eur J Heart Fail 14: 211-218. [Crossref]
79. Lowres N, Neubeck L, Redfern J, Freedman SB (2013) Screening to identify unknown atrial fibrillation. A systematic review. Thromb Haemost 110: 213-222. [Crossref]

80. Lowres N, Neubeck L, Salkeld G, Krass I, McLachlan AJ, et al. (2014) Feasibility and cost-effectiveness of stroke prevention through community screening for atria fibrillation using iPhone ECG in pharmacies. The SEARCH-AF study. Thromb Haemost 111, 1167-1176. [Crossref]

81. Potpara TS, Polovina MM, Marinkovic JM, Lip GY (2013) A comparison of clinical characteristics and long-term prognosis in asymptomatic and symptomatic patients with first-diagnosed atrial fibrillation: the Belgrade Atrial Fibrillation Study. Int $J$ Cardiol 168, 4744-4749. [Crossref]

82. Jang SJ, Kim MS, Park HJ, Han S, Kang DH, et al. (2013) Impact of heart failure with normal ejection fraction on the occurrence of ischaemic stroke in patients with atrial fibrillation. Heart 99: 17-21.

83. Banerjee A, Taillandier S, Olesen JB, Lane DA, Lallemand B, et al. (2012) Ejection fraction and outcomes in patients with atrial fibrillation and heart failure: the Loire Valley Atrial Fibrillation Project. Eur J Heart Fail 14: 295-301. [Crossref]

84. Potpara TS, Polovina MM, Licina MM, Marinkovic JM, Lip GY (2013) Predictors and prognostic implications of incident heart failure following the first diagnosis of atrial fibrillation in patients with structurally normal hearts: the Belgrade Atrial Fibrillation Study. Eur J Heart Fail 15: 415-424. [Crossref]

85. Sweeney MO (2001) Sudden death in heart failure associated with reduced left ventricular function: substrates, mechanisms, and evidence-based management, Part II. Pacing Clin Electrophysiol 24: 1002-1022. [Crossref]

86. Whang W, Mittleman MA, Rich DQ, Wang PJ, Ruskin JN, et al. (2004) Heart failure and the risk of shocks in patients with implantable cardioverter defibrillators: results from the Triggers Of Ventricular Arrhythmias (TOVA) study. Circulation 109: 13861391. [Crossref]

87. Baldasseroni S, Opasich C, Gorini M, Lucci D, Marchionni N, et al. (2002) Left bundle-branch block is associated with increased 1-year sudden and total mortality rate in 5517 outpatients with congestive heart failure: a report from the Italian network on congestive heart failure. Am Heart J 143: 398-405. [Crossref]

Copyright: (C2020 Albakri A. This is an open-access article distributed under the terms of the Creative Commons Attribution License, which permits unrestricted use, distribution, and reproduction in any medium, provided the original author and source are credited. 